\title{
PRODUTIVIDADE DE CANA-DE-AÇÚCAR EM CICLOS AGRÍCOLAS CONSECUTIVOS APÓS PRÉ-CULTIVO DE ESPÉCIES ADUBOS VERDES
}

\author{
Edmilson José Ambrosano ${ }^{1}$, Heitor Cantarella ${ }^{2}$, Gláucia Maria Bovi Ambrosano ${ }^{3}$, Eliana \\ Aparecida Schammas ${ }^{4}$, Fábio Luis Ferreira Dias ${ }^{1}$, Fabrício Rossi ${ }^{1}$, Paulo Cesar Ocheuze \\ Trivelin ${ }^{5}$, Takashi Muraoka ${ }^{5}$, Rozario Azcón ${ }^{6}$ \\ ${ }^{1}$ Pólo Regional Centro Sul, Apta, Piracicaba, SP- E-mail: ambrosano@apta.sp.gov.br \\ 2 Instituto Agronômico de Campinas \\ ${ }^{3}$ Universidade de Campinas \\ 4 Instituto de Zootecnia, Nova Odessa, SP \\ ${ }^{5}$ Centro de Energia Nuclear na Agricultura, Piracicaba, SP \\ ${ }^{6}$ Estação Experimental de Zaidín, Granada, Espanha
}

\section{RESUMO}

O presente trabalho foi conduzido no período de novembro de 2006 a junho de 2010, com objetivo de avaliar a produção de cana-de-açúcar, em três ciclos agrícolas consecutivos, após précultivo de espécies adubos verdes. Os adubos verdes Crotalária-júncea, e Guandu IAC-fava larga apresentaram a maior produção de material vegetal fresco e seco. Para a produção de colmos e açúcar, com exceção ao tratamento mucuna-cinza que apresentou um comportamento semelhante à testemunha sem adubo verde, todos os adubos verdes aumentaram a produtividade, produzindo, na média de três cortes, $25 \%$ mais que o tratamento sem adubo verde. Os adubos verdes reduziram a ocorrência de plantas daninhas até o primeiro corte com destaque para as mucunas verde e cinza. Não foram observadas alterações na infecção natural por micorrizas, nem na infestação por broca da cana nos tratamentos com adubos verdes em relação à testemunha.

Palavras-chave: Adubação verde, agricultura sustentável, micorrizas

\section{SUGARCANE YIELD ON CONSECUTIVE CUTS AFTER PRE-CULTIVATION OF GREEN MANURE SPECIES}

\begin{abstract}
This work was carried out to evaluate the sugarcane yield after a pre-cultivation of green manure species from November 2006 to June 2010. Sunn hemp and pigeon pea IAC-fava larga showed a higher production of fresh and dried plant material. For the production of stalks and sugar, except for the gray velvet beans treatment, that showed a behavior similar to the treatment without green manure. All the treatments with green manure increased yield, producing an


average of $25 \%$ more than the treatment without green manure. Green manures had an effect on weed control with emphasis on green and gray velvet beans until the first cut of sugarcane. No changes were observed in the natural infection by mycorrhizal fungi, nor infestation by the sugarcane borer in the treatments with green manure in relation to the control.

Keywords: Green manure, sustainable agriculture, mycorrhizal fungi

\section{INTRODUÇÃO}

No Brasil, em pouco mais de $1 \%$ das áreas agricultáveis plantam-se 9,6 milhões de hectares de cana $(38 \%$ da área do Reino Unido e $16 \%$ do território francês), produzindo matéria-prima que permite a fabricação de bioenergia natural, limpa e renovável (IBGE, 2010).

A prática de produzir plantas que permanecem na área com o objetivo de manter ou melhorar sua fertilidade para o cultivo subsequente é denominada de adubação verde (ESPÍNDOLA et al., 2004). Esta prática milenar causa alterações nas características físicas, químicas e biológicas do solo, trazendo benefícios à cultura subsequente. Do ponto de vista social, a adubação verde contribui para a autosuficiência do produtor em relação aos insumos externos utilizados para 0 incremento da fertilidade do solo (AMBROSANO et al., 2005).

O cultivo da cana-de-açúcar no centro sul do Brasil está apto a receber outros cultivos nas áreas de reforma do canavial, que ficam meses desprovidas de vegetação, sujeitas a ocorrência de elevadas precipitações pluviométricas (cerca de 950 milímetros em seis meses), agravando os problemas decorrentes da erosão (CÁCERES \& ALCARDE, 1995).

Dependendo do manejo varietal e da época de corte quanto aos ambientes de produção a longevidade do canavial pode chegar a quatro ou oito cortes, sendo que no ultimo corte que antecede a reforma a canade-açúcar deverá ser retirada até agosto. Após esse período efetua-se novo plantio de plantas de cobertura de outubro a novembro, com manejo previsto para janeiro e fevereiro e plantio da cana-de-açúcar em março. Dessa forma se preserva o solo e podem-se produzir grãos, agroenergia, ou simplesmente, melhorar o solo através da adubação verde (AMBROSANO et al., 1999).

Os adubos verdes em áreas de reforma da cana-de-açúcar constituem, assim, uma alternativa importante para reciclagem de nutrientes (MASCARENHAS 
et al., 1994), com economia da adubação nitrogenada e geração de renda (AMBROSANO et al., 2010; 2011).

Outra associação microbiológica importante para as leguminosas usadas em pré-cultivo à cultura da cana-de-açúcar, além da associação com rizóbios para fixação simbiótica do nitrogênio, é a formada pelos fungos micorrízicos arbusculares (FMA). Estes fungos estão presentes em mais de $80 \%$ das espécies vegetais (AZCÓN et al., 1991).

Utilizar uma cultura cujas raízes são colonizadas por fungos micorrízicos pode beneficiar as plantas que são cultivadas em sequência (PANJA \& CHAUDHURI, 2004), melhorando ainda mais o ambiente de produção (ESPÍNDOLA et al.,1998).

Aliado a isso, os adubos verdes podem ser uma alternativa importante no controle de plantas daninhas devido a mudança da pressão de seleção, com alteração dos padrões de distúrbios (ARÉVALO et al., 2004). Assim, o presente trabalho teve como objetivo avaliar e caracterizar a produção de material vegetal fresco e seco de plantas utilizadas em précultivo a cana-de-açúcar, sua infecção natural por fungos micorrízicos arbusculares (FMA), sua relação com o controle de plantas daninhas e seus efeitos na produtividade agrícola e industrial e na ocorrência de broca, Diatraea saccharalis, na cana-planta.

\section{MATERIAL E MÉTODOS}

$\mathrm{O}$ experimento foi conduzido em Piracicaba, SP, $\left(22^{\circ} 42^{\prime} \mathrm{S}, 47^{\circ} 38^{\prime} \mathrm{W}\right.$ e $560 \mathrm{~m}$ altitude), em Argissolo Vermelho Escuro, distrófico, textura argilosa, no período de novembro de 2006 a junho de 2010.

As características químicas iniciais do Argissolo Vermelho Escuro revelaram: M.O. $=26 \mathrm{~g} \mathrm{dm}^{-3}, \mathrm{P}$ (resina) $=3 \mathrm{mg} \mathrm{dm}^{-3}, \mathrm{~K}$, Ca e $\mathrm{Mg}=0,7 ; 7 ; 6 \mathrm{mmol}_{\mathrm{c}} \mathrm{dm}^{-3} ; \mathrm{pH}\left(\mathrm{CaCl}_{2}\right)$ $=4,1 ; \mathrm{SB}=13,7 \mathrm{mmol}_{\mathrm{c}} \mathrm{dm}^{-3} ; \mathrm{CTC}=63,7$ $\mathrm{mmol}_{\mathrm{c}} \mathrm{dm}^{-3} ; \mathrm{V} \%=22$. Não foi aplicado corretivo nem fertilizante para os adubos verdes, fazendo com que essas plantas se desenvolvessem apenas dispondo do efeito residual dos fertilizantes utilizados na canade-açúcar.

Apesar de constatada a necessidade da correção da acidez do solo através da observação da análise de solo, seguiu-se a recomendação de Mascarenhas et al. (1994) que afirmaram que as leguminosas respondem mais à fertilidade natural do solo do que a adubação direta. $\mathrm{O}$ experimento foi conduzido sem essa correção e sem adubação, sendo que, dessa forma, as leguminosas puderam expressar seu potencial de produção. Essas condições de 
solo foram semelhantes às observadas por Ambrosano et al. (2011a) onde, num solo com saturação por bases $(\mathrm{V} \%)$ de 22 , a crotalária-júncea IAC-1 produziu $9 \mathrm{t} \mathrm{ha}^{-1}$.

O delineamento foi em blocos casualizados com 5 repetições com 13 tratamentos, sendo 12 espécies de plantas utilizadas em pré-cultivo a cana-de-açúcar, sendo elas: amendoim (Arachis hypogaea L.), IAC-Tatu e IAC-Caiapó, Crotaláriajúncea IAC-1 (Crotalaria juncea L.), Mucuna-preta (Mucuna aterrimum Piper and Tracy), Soja IAC-23 (Glycine max L. Merrill), Girassóis (Helianthus annuus L.), IAC-Uruguai e IAC-Iarama, Feijão-mungo (Vigna radiata L. Wilczek), Mucuna-cinza (Mucuna cinerea L.), Mucuna-verde (Mucuna pruriens (L.) DC. var. verde), Guandus (Cajanus cajan L.) IAC-fava larga e Guandu IAC-Anão e um tratamento testemunha, sem adubo verde.

Quando se estudou o efeito nas plantas daninhas e na produtividade de cana e do açúcar utilizou-se de 13 tratamentos. Quando se estudou a produção da biomassa e os nutrientes nos adubos verdes, foram considerados os primeiros 12 tratamentos.

A semeadura dos tratamentos foi realizada em primeiro de novembro de 2006 no espaçamento de $0,5 \mathrm{~m}$ entre linhas. O tamanho de cada parcela foi de $7 \mathrm{~m}$ de largura e $8 \mathrm{~m}$ de comprimento. A colheita e avaliação dos adubos verdes foi feita em uma área útil de $1 \mathrm{~m}^{2}$ da área central de cada parcela experimental $(7 \times 8 \mathrm{~m})$ em março de 2007. A produtividade de grãos dos amendoins, soja, feijão-mungo e girassóis, utilizados em pré-cultivo da cana-de-açúcar também foram avaliados. Desse material vegetal da parte aérea coletou-se uma amostra para determinação de umidade em estufa de circulação forçada de ar, a uma temperatura de $60^{\circ} \mathrm{C}$. Esse material vegetal seco foi moído, em moinhos de faca tipo Willey, e os teores de $\mathrm{N}$ e $\mathrm{C}$ foram determinados em espectrômetro de massa usando metodologia descrita por Trivelin et al. (1973). A Fixação biológica do nitrogênio $(\mathrm{FBN})$ foi determinada através da metodologia da abundância natural de ${ }^{15} \mathrm{~N}$ técnica do delta $\left(\delta^{15} \mathrm{~N}\right)$ (SHEARER \& KOHL, 1986), e a cana-de-açúcar foi utilizada como padrão de planta não fixadora, e as determinações químicas de teores de nutrientes, segundo Bataglia et al. (1983).

As avaliações das plantas daninhas foram realizadas no centro da parcela experimental, em uma área útil de $1 \mathrm{~m}^{2}$, e foram feitas logo após a colheita e avaliação dos adubos verdes antes do plantio da canade-açúcar. O material vegetal foi seco em 
estufa de circulação forçada de ar a uma temperatura de $60^{\circ} \mathrm{C}$ até peso constante.

Nessa ocasião foram amostradas as raízes das plantas utilizadas em pré-cultivo para avaliar a porcentagem de colonização natural dos fungos micorrízicos arbusculares (FMAs).

O método desenvolvido por Philips \& Hyman (1970) foi utilizado para estimativa da infecção das raízes por micorrizas, observando as raízes coloridas em microscópio óptico utilizando-se de uma placa reticulada, segundo Giovanetti \& Mosse (1980).

Após a colheita, a biomassa das plantas foi triturada e mantida sobre o solo e a sulcagem para plantio da cana-de-açúcar foi feita diretamente sobre a cobertura vegetal.

Foi feito o plantio da cana-de-açúcar (variedade IAC87-3396) em cada parcela, usando o espaçamento de 1,4 m entre linhas. A cana-de-açúcar foi adubada com $500 \mathrm{~kg}$ $\mathrm{ha}^{-1}$ da formulação 08-28-16 $\left(\mathrm{N}, \mathrm{P}_{2} \mathrm{O}_{5}, \mathrm{~K}_{2} \mathrm{O}\right)$ no plantio. Após cada corte aplicaram-se 500 $\mathrm{kg} \mathrm{ha}{ }^{-1}$ da formulação 20-5-20 (N, $\mathrm{P}_{2} \mathrm{O}_{5}$, $\mathrm{K}_{2} \mathrm{O}$ ). Não se utilizou de irrigação e a partir da primeira soqueira o manejo das plantas daninhas foi efetuado após cada corte da cana-de-açúcar utilizando-se do herbicida metribuzin (1.92 $\mathrm{L}^{\mathrm{ha}^{-1}}$ do ingrediente ativo).

A cana-de-açúcar se desenvolveu durante o período de 16 meses e foi colhida pela primeira vez em 19 de agosto de 2008, após 12 meses se efetuou o segundo corte em 17 de agosto de 2009 e o terceiro corte foi feito 10 meses após o segundo em 10 de junho de 2010, sendo que em todas as épocas foi avaliado o peso em $\mathrm{kg}$ de uma amostra de cana-de-açúcar coletada em três seguimentos de $2 \mathrm{~m}$ lineares contínuos, no centro da parcela experimental, e calculada sua produtividade.

Foram tomados dez colmos de cana seguidos na linha em cada tratamento (TANIMOTO, 1964) para determinação de Brix \%, pol\%, e com base na produtividade de colmos se calcula a tonelada de pol por hectare (TPH).

Da mesma forma foram colhidos 10 colmos para determinação de ocorrência de incidência de broca da cana-de-açúcar, Diatraea saccharalis, de acordo com Gallo et al. (2002).

A análise estatística dos dados de produtividade agrícola e açúcar foram realizados utilizando-se o conceito de medidas repetidas no tempo e $\mathrm{o}$ procedimento MIXED do programa SAS. 
Para a escolha da matriz de variância e covariância foi utilizado o critério de informação de AKAIKE (LITTEL et al., 1996), selecionando-se a que possui menor valor para esse parâmetro (AKAIKE, 1974 e SAS 8.2). No modelo estatístico, os efeitos de tratamento, épocas de amostragem e suas interações foram considerados fixos e 0 efeito de bloco considerado aleatório. As médias ajustadas dos efeitos fixos foram obtidas através da opção "LSMEANS" e as comparações de médias realizadas através do teste Tukey-Kramer $(\alpha=0.05)$.

As comparações entre médias de tratamentos, para as demais variáveis, foram feitas pelo teste de Scott-Knott, para agrupamento de médias $(\alpha=0.05)$ utilizando-se o programa estatístico SISVAR (FERREIRA, 2008). Os dados referentes a produtividade dos adubos verdes seco $(\mathrm{kg}$ $\left.\mathrm{ha}^{-1}\right)$, nutrientes, $\mathrm{N}$ e $\mathrm{K} \quad\left(\mathrm{kg} \mathrm{ha}^{-1}\right)$ foram transformados em raiz quadrada e $\mathrm{P}\left(\mathrm{kg} \mathrm{ha}^{-1}\right)$ e Ca $\left(\mathrm{kg} \mathrm{ha}^{-1}\right)$ em $\log (\mathrm{X})$ a fim de atender as pressuposições da análise da variância.

\section{RESULTADOS E DISCUSSÃO}

A análise dos dados agrupou as produções de material vegetal úmida em 4 agrupamentos. O grupo que se destacou foi crotalária-júncea IAC-1, e o guandu IACfava larga (Tabela 1), concordando com Mascarenhas et al. (1994) e Ambrosano et al. (2011). No segundo agrupamento ficou o guandu IAC-Anão e as mucunas, preta, verde e cinza. No terceiro e quarto agrupamento ficaram as plantas alimentícias com destaque para o Girassol IAC-Uruguai, que produziu 28,2 ton $\mathrm{ha}^{-1}$ de massa vegetal úmida, cerca de 9,5 ton $\mathrm{ha}^{-1}$ de massa seca (Tabela 1).

O déficit hídrico é o principal fator limitante para o desenvolvimento do girassol em solos agricultáveis, e constitui-se na maior causa de variabilidade dos rendimentos de grãos de um ano para outro. Após a semeadura a precipitação foi baixa, aumentando com o passar do tempo (Figura 1). Ambrosano et al. (2010) encontraram produções de material vegetal seco na ordem de $15 \mathrm{t} \mathrm{ha}^{-1}$ com uma produtividade de grãos de $1800 \mathrm{~kg} \mathrm{ha}^{-1}$ o que proporcionou a melhor produtividade de colmos da cana-de-açúcar. Esses valores de produtividade estão muito acima dos encontrados no presente trabalho que foi de 9,5 $\mathrm{t} \mathrm{ha}^{-1}$ e com produtividade de grãos na ordem de $1400 \mathrm{~kg} \mathrm{ha}^{-1}$ (Tabela 1).

Apesar da baixa produtividade de massa seca dos girassóis, seu pré-cultivo nas áreas de reforma ainda promoveram bom desempenho da cana-de-açúcar, com médias de produtividade, em três cortes, de 100 a 98 ton $\mathrm{ha}^{-1}$ respectivamente para os cultivares IAC-Uruguai e IAC-Iarama, isso pode ser 
devido a sua elevada relação $\mathrm{C}: \mathrm{N}$ de 107 e

86 respectivamente para IAC-Uruguai e
IAC-Iarama, que fez com que o efeito da matéria orgânica fosse mais duradouro.

Tabela 1. Produção de material vegetal úmido e seco de adubos verdes, produção de grãos das plantas alimentícias e infecção natural por fungos micorrizicos arbusculares (FMA), Piracicaba-SP, 2007.

\begin{tabular}{|c|c|c|c|c|}
\hline Tratamentos & $\begin{array}{l}\text { Adubo verde } \\
\text { úmido* }\end{array}$ & $\begin{array}{l}\text { Adubo verde } \\
\text { seco* }\end{array}$ & $\begin{array}{l}\text { Produção de } \\
\text { grãos }\end{array}$ & Infecção FMA \\
\hline & & $\mathrm{MG} \mathrm{ha}^{-1}$ & ------------ & ------\%----- \\
\hline Crotalária-júncea IAC-1 & $62,1 \mathrm{a}$ & $24,4 \mathrm{a}$ & - & $41 \mathrm{a}$ \\
\hline Guandu IAC-Fava Larga & $67,5 \mathrm{a}$ & $22,7 \mathrm{a}$ & - & $40 \mathrm{a}$ \\
\hline Guandu IAC-anão & $40,6 \mathrm{~b}$ & $14,8 \mathrm{~b}$ & - & $44 \mathrm{a}$ \\
\hline Mucuna-preta & $46,3 \mathrm{~b}$ & $10,4 \mathrm{c}$ & - & $53 \mathrm{a}$ \\
\hline Mucuna-verde & $43,5 \mathrm{~b}$ & $9,3 \mathrm{c}$ & - & 39 a \\
\hline Mucuna-cinza & $35,6 \mathrm{~b}$ & $7,1 \mathrm{c}$ & - & $40 \mathrm{a}$ \\
\hline Girassol IAC-Uruguai & $28,2 \mathrm{c}$ & $9,5 \mathrm{c}$ & $1,46 \mathrm{~b}$ & $36 \mathrm{a}$ \\
\hline Soja IAC-23 & $21,2 \mathrm{c}$ & $9,0 \mathrm{c}$ & $2,97 \mathrm{a}$ & $52 \mathrm{a}$ \\
\hline Girassol IAC-Iarama & $15,3 \mathrm{c}$ & $6,5 \mathrm{~d}$ & $1,03 \mathrm{~b}$ & $48 \mathrm{a}$ \\
\hline Amendoim IAC-Tatu & $7,9 \mathrm{~d}$ & $2,6 \mathrm{~d}$ & $1,25 \mathrm{~b}$ & $30 \mathrm{a}$ \\
\hline Amendoim IAC-Caiapó & $4,7 \mathrm{~d}$ & $1,5 \mathrm{~d}$ & $3,19 \mathrm{a}$ & $37 \mathrm{a}$ \\
\hline Feijão-Mungo & $7,2 \mathrm{~d}$ & $2,7 \mathrm{~d}$ & $3,07 \mathrm{a}$ & $36 \mathrm{a}$ \\
\hline $\mathrm{CV}^{*}(\%)$ & 18,11 & 19,66 & 24,97 & 40,86 \\
\hline
\end{tabular}

Médias seguidas de mesma letra pertencem ao mesmo agrupamento peloteste de Scott-Knott a $5 \%$ de probabilidade.

* Dados transformados em $\mathrm{X}^{1 / 2}$, para fins de análise estatística.

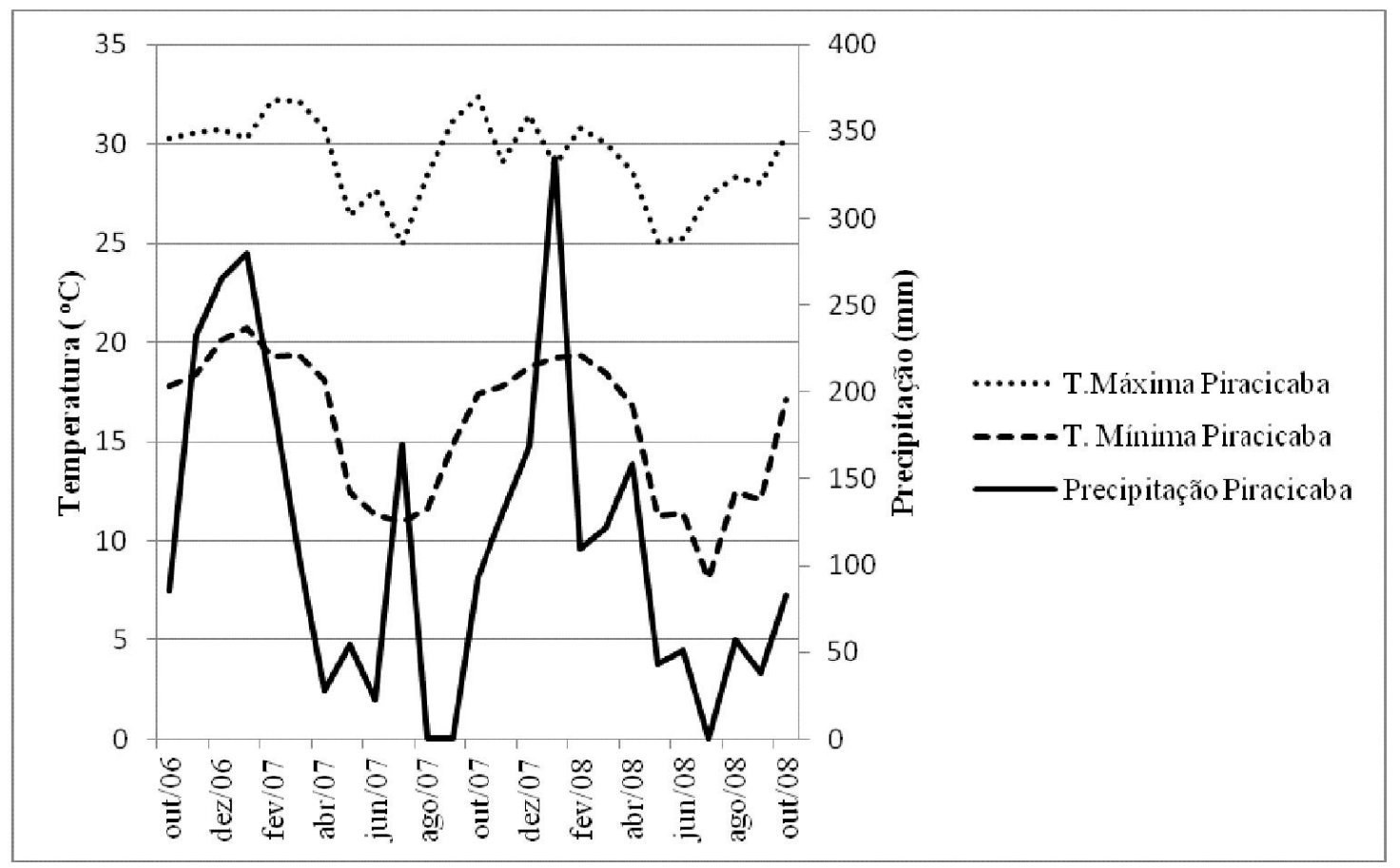

Figura 1.Dados de temperatura máxima, mínima e precipitação de outubro de 2006 a outubro de 2008, em Piracicaba-SP. 
A produção de biomassa seca observada nesse experimento para crotaláriajúncea e mucuna-preta são superiores as encontradas por Ambrosano et al. (2011a), que foi da ordem de 9 ton $\mathrm{ha}^{-1}$ e Cáceres \& Alcarde (1995), que determinaram valores de biomassa seca de 7 e 3 ton $\mathrm{ha}^{-1}$ para crotalária-júncea e mucuna-preta respectivamente e por Ambrosano et al. (2010), que encontraram biomassa seca de 6 e 5 ton ha $^{-1}$ para crotalária-júncea e mucunapreta respectivamente, indicando que os agricultores que adotarem essa prática devem ter sucesso, desde que a semeadura dos adubos verdes não ultrapasse o mês de dezembro.

Houve diferença na produtividade de grãos dos cultivares de amendoins (Tabela 1), sendo que o IAC-Caiapó apresentou alta produtividade em relação ao IAC-Tatu, segundo Quaggio \& Godoy (1996), contudo essa sucessão traz renda ao produtor o que pode tornar o uso do amendoim viável. Ambrosano et al. $(2010 ; 2011)$ encontraram produtividades baixas para os mesmos cultivares de amendoim e um custo de produção muito alto para as condições de Piracicaba. Isso pode ser devido a falta de prática de rotação nessa região, sendo que a região produtora de Ribeirão Preto pratica rotação com amendoim com excelentes resultados.

Quanto às produções de grãos das plantas alimentícias, o feijão-mungo, a soja IAC-23, e o amendoim IAC-Caiapó ficaram no agrupamento das alimentícias mais produtivas, não ocorrendo diferença entre os amendoins IAC-Tatu e os girassóis IACUruguai e IAC-Iarama (Tabela 1).

O feijão-mungo apresenta uma alternativa importante de geração de renda ao produtor por ser planta de ciclo curto (80 dias), apresentar boa produtividade (3.070 $\mathrm{kg} \mathrm{ha}^{-1}$ ) e pela possibilidade de agregação de valor ao produto final que seria a produção de brotos comestíveis (Moyashi), segundo Ambrosano et al. (2003).

Além disso, essa planta é a que apresentou o maior potencial de fixação simbiótica do nitrogênio, sendo que do $\mathrm{N}$ presente na sua composição $98 \%$ veio da FBN.

As plantas utilizadas em pré-cultivo apresentaram, com exceção da mucunapreta, e soja IAC-23, menos da metade de seu sistema radicular infectado naturalmente por fungos micorrízicos arbusculares (Tabela 1), contudo vale ressaltar que isso reflete no aumento do sistema radicular melhorando o desempenho na absorção de nutrientes e água (AZCÓN, 1999). 
Segundo Espíndola et al. (1998), o pré-cultivo de leguminosas como adubo verde aumentou o número de propágulos infectivos de fungos micorrízícos com consequente aumento na produtividade de batata-doce. Ambrosano et al. (2010) observaram que a infecção natural por micorrizas se correlacionou positivamente com a altura da cana-de-açúcar quando do pré-cultivo de leguminosas adubo verde, em áreas de renovação do canavial.

A quantidade de material vegetal seco que permanecerá no solo, por sua vez, é um item indispensável para avaliação dos efeitos dos adubos verdes no solo e na emergência das plantas daninhas. A crotalária continuou com $\mathrm{o}$ melhor rendimento de massa vegetal seca, juntamente com os guandus IAC-fava larga, os quais não diferiram entre si (Tabela 1).

Quanto às plantas alimentícias, o girassol IAC-Uruguai apresentou melhor resultado na produção de material vegetal fresco, não ocorrendo diferença entre a soja IAC-23 e o girassol IAC-Iarama (Tabela 1).

A broca da cana-de-açúcar (Diatraea saccharalis) é a principal praga da cana-deaçúcar no Brasil. Os danos ocasionados na cultura são a perda de produtividade da cana e a diminuição da pureza do caldo, diminuindo o rendimento em açúcar e álcool.

Não foi observada diferença entre a testemunha e os demais tratamentos (Tabela 2). Segundo estudos já realizados, o controle se faz necessário quando é encontrada uma intensidade de infestação igual ou superior a $3 \%$. Conclui-se que os adubos verdes não interferem na infestação natural da broca, sendo assim essa prática pode ser recomendada com segurança nas áreas de reforma de canavial e que apenas em dois tratamentos foram observados níveis que necessitariam de controle.

$\mathrm{O}$ número de perfilhos encontrado aos 120 dias após plantio da cana-de-açúcar foi superior para o pré-cultivo de mucunaverde, indicando que a diminuição de plantas daninhas pode estar associada ao melhor desempenho desse tratamento frente aos demais (Tabela 2).

A análise dos dados permitiu separar os tratamentos em três agrupamentos, sendo um as plantas que controlaram o mato melhor que as capinas manuais realizadas no tratamento testemunha, um grupo intermediário, onde se encontra a testemunha capinada, e outro agrupamento que não apresentou controle algum sobre o mato (Tabela 2). Algumas espécies de leguminosas utilizadas no experimento 
apresentaram controle de mato adequado, semelhante ao tratamento mantido capinado, através de três capinas realizadas no período de primeiro de novembro de 2006 até primeiro de março de 2007, sendo elas as mucunas, verde, cinza e preta, e o guandu IAC-fava larga. Para as alimentícias pode-se destacar o bom controle da soja IAC-23 e do amendoim IAC-Caiapó, sendo que este último apresentou porte menor, hábito de crescimento mais rasteiro e ciclo de 130 dias, o que possibilita bom controle do mato.

Em levantamento realizado na área experimental observou-se as seguintes plantas daninhas que predominaram nas amostragens e para as quais os adubos verdes apresentaram efetivo controle: CYPRO- Cyperus rotundus L.; PANMAPanicum maximum Jacq.; BRAPLBrachiaria plantagina (Link) Hitchc.; BRADC- Brachiaria decumbens Stapf.; e CYNDA- Cynodon dactylon (1.) Pers e ROOEX-Rottboellia exaltatt L. As plantas de cobertura com excelente controle do mato foram mucuna-cinza e mucuna-verde (Tabela 2). Resultados semelhantes foram apresentados por Erasmo et al. (2004) que encontraram eficiente controle do mato pelas mucunas por até 60 dias após o corte desse adubo verde.
Esse comportamento pode auxiliar no controle de plantas daninhas da cultura subsequente, ou seja, a cana-de-açúcar, uma vez que o período crítico de competição vai da emergência dos brotos de cana até os 30 dias e com a utilização dessas coberturas a área permanece por mais tempo com baixa ocorrência de plantas daninhas (ARÉVALO et al., 2004).

Esse efetivo controle sobre as plantas daninhas pode ser devido ao porte desses adubos verdes, que apresentam crescimento vigoroso e interfere diretamente na incidência de luz ao solo e poderia impedir a emergência de outras plantas, além do fato de liberarem substâncias químicas alelopáticas.

Essa ação alelopática impede ou diminui a germinação e o desenvolvimento das plantas daninhas (FAVERO et al., 2001). Os compostos químicos responsáveis pela alelopatia são denominados aleloquímicos e cada espécie pode produzir um conjunto diferente de aleloquímicos, com ação diferenciada sobre os componentes da comunidade em que está inserida (PUTNAM et al., 1983), dependendo, principalmente, da quantidade do material vegetal depositado na superfície, do tipo de solo, da população microbiana e das condições climáticas (PITELLI, 1997). Os aleloquímicos são 
elaborados pelas células com finalidades específicas, e uma única planta pode produzir centenas deles (SWAIN, 1977).

A produtividade agrícola da cana-deaçúcar medida em toneladas de colmos por hectare $(\mathrm{TCH})$ e da quantidade de açúcar produzida em toneladas de pol por hectare (TPH) na média de três cortes (Tabela 3), foi beneficiada pelos tratamentos que tiveram um efeito positivo e duradouro promovendo melhores resultados até o terceiro corte, a exceção da mucuna cinza que produziu igual ao tratamento testemunha (sem adubo verde). Resultados semelhantes foram obtidos por Mascarenhas et al. (1994) e Cáceres \& Alcarde (1995).

Mascarenhas et al. (1994), encontraram que o emprego da crotaláriajúncea em cana-de-açúcar, supera em produtividade à aplicação ao solo de $40 \mathrm{~kg}$ $\mathrm{ha}^{-1}$ de N-mineral.

Ambrosano et al. (2005), aplicaram conjunta e separadamente nitrogênio na forma de crotalária-júncea $\left(196 \mathrm{~kg} \mathrm{ha}^{-1}\right.$ de N) e nitrogênio mineral $\left(70 \mathrm{~kg} \mathrm{ha}^{-1}\right.$ de N) e observaram que a cana-planta absorveu quantidades de $\mathrm{N}$ semelhantes, provenientes de ambas as fontes, indicando que a fonte orgânica pode suprir completamente as demandas de $\mathrm{N}$ da cana-de-açúcar, entretanto ao utilizar as duas fontes conjuntamente observou-se maior rendimento na produção de colmos.

A produtividade de açúcar do melhor tratamento foi $23 \%$ maior ao da testemunha sem adubo verde (Tabela 3), resultado que se iguala ao obtido por Mascarenhas et al. (1994) e Cáceres \& Alcarde (1995), que encontraram um incremento de $2,98 \mathrm{t}$ de açúcar por hectare, e os efeitos da adubação verde foram sentidos mais na cana-planta. Esses resultados confirmam os valores da literatura onde a cana-de-açúcar apresenta as melhores produtividades nas safras que sucedem à do plantio quando deverá ser recomendada uma fertilização adequada, uma vez que nos demais anos, além do baixo vigor da soqueira, surgem e/ou se agravam outros problemas, como: nível nutricional, compactação, pragas e doenças. Orlando Filho et al. (1999) observaram queda na produtividade agrícola ao longo dos ciclos, sendo mais drástica da cana-planta (cana de ano e meio) para a primeira soca. Concluíram que à cana-planta e as três soqueiras subsequentes responderam linearmente a adubação nitrogenada até a dose de $120 \mathrm{~kg} \mathrm{ha}^{-1}$. Chapman et al. (1983) constataram que as soqueiras requerem maior quantidade de $\mathrm{N}$ para produzirem em relação à cana-planta. 
Isso provavelmente se deve à diminuição das reservas de $\mathrm{N}$ no solo ao longo do ciclo.

Ambrosano et al. (2010), desenvolveram experimento utilizando-se de sete espécies de plantas em áreas de reforma do canavial e encontraram aumentos de 50\% na produção de açúcar nos tratamentos com girassol IAC-Uruguai e 35\% para crotaláriajúncea e Ambrosano et al. (2011), que trabalharam com quatro espécies de plantas, encontraram um rendimento econômico que chegou a $150 \%$ maior nos tratamentos com crotalária júncea que o tratamento sem adubo verde.

A qualidade da biomassa formada com adubação verde é determinada pela sua relação carbono nitrogênio $\mathrm{C} / \mathrm{N}$ e no caso das leguminosas essa relação é sempre baixa devido a presença de nitrogênio que veio da fixação biológica. A relação $\mathrm{C} / \mathrm{N}$ encontrada no experimento para as leguminosas foi baixa, chegando a 11 para a mucuna-preta. $\mathrm{O}$ amendoim Tatu e o feijão-mungo apresentaram valores maiores, contudo abaixo de 40 (Tabela 6).

Tabela 2. Comparação entre tratamentos para produção de matéria úmida e seca de plantas daninhas amostradas na época do corte dos adubos verdes, número de perfilhos encontrado aos 120 dias após plantio da cana-de-açúcar e percentagem de infestação por broca amostrada na época de colheita industrial da cana-planta, Piracicaba-SP, 2007.

\begin{tabular}{lcccc}
\hline Tratamentos & $\begin{array}{c}\text { Plantas daninhas } \\
\text { matéria úmida* }\end{array}$ & $\begin{array}{c}\text { Plantas } \\
\text { daninhas } \\
\text { matéria seca* }\end{array}$ & $\begin{array}{c}\text { Perfilhos em } \\
3 \mathrm{~m} \text { lineares }\end{array}$ & $\begin{array}{c}\text { Percentagem } \\
\text { de broca }\end{array}$ \\
\hline Mucuna-verde & $---------------\mathrm{Kg} \mathrm{m}^{-2}-----------$ & Número & $\%$ \\
Mucuna-cinza & $0,23 \mathrm{c}$ & $0,06 \mathrm{c}$ & $41 \mathrm{a}$ & $2,0 \mathrm{a}$ \\
Guandu IAC-fava larga & $0,33 \mathrm{c}$ & $0,05 \mathrm{c}$ & $35 \mathrm{~b}$ & $0,8 \mathrm{a}$ \\
Amendoim IAC-Caiapó & $1,73 \mathrm{~b}$ & $0,59 \mathrm{~b}$ & $32 \mathrm{~b}$ & $3,4 \mathrm{a}$ \\
Mucuna-preta & $1,97 \mathrm{~b}$ & $0,63 \mathrm{~b}$ & $39 \mathrm{~b}$ & $3,0 \mathrm{a}$ \\
Soja IAC-23 & $1,64 \mathrm{~b}$ & $0,44 \mathrm{~b}$ & $38 \mathrm{~b}$ & $2,2 \mathrm{a}$ \\
Testemunha (campinada) & $2,00 \mathrm{~b}$ & $0,50 \mathrm{~b}$ & $30 \mathrm{~b}$ & $2,0 \mathrm{a}$ \\
Crotalária-júncea IAC-1 & $1,28 \mathrm{~b}$ & $0,48 \mathrm{~b}$ & $29 \mathrm{~b}$ & $1,4 \mathrm{a}$ \\
Amendoim IAC-Tatu & $2,13 \mathrm{a}$ & $0,75 \mathrm{a}$ & $36 \mathrm{~b}$ & $1,6 \mathrm{a}$ \\
Girassol IAC-Uruguai & $4,82 \mathrm{a}$ & $1,46 \mathrm{a}$ & $34 \mathrm{~b}$ & $2,0 \mathrm{a}$ \\
Feijão-Mungo & $4,45 \mathrm{a}$ & $0,92 \mathrm{a}$ & $35 \mathrm{~b}$ & $1,9 \mathrm{a}$ \\
Guandu IAC-anão & $3,70 \mathrm{a}$ & $0,99 \mathrm{a}$ & $36 \mathrm{~b}$ & $3,6 \mathrm{a}$ \\
Girassol IAC-Iarama & $3,38 \mathrm{a}$ & $0,82 \mathrm{a}$ & $37 \mathrm{~b}$ & $0,9 \mathrm{a}$ \\
\hline CV*(\%) & $3,25 \mathrm{a}$ & $1,17 \mathrm{a}$ & $35 \mathrm{~b}$ & $2,7 \mathrm{a}$ \\
\hline
\end{tabular}

Médias seguidas de mesma letra pertencem ao mesmo agrupamento peloteste de Scott-Knott a $5 \%$ de probabilidade.

*Dados transformados em $\log (\mathrm{x}+1)$ para fins de análise de variância. 


\section{PRODUTIVIDADE DE CANA-DE-AÇÚCAR EM CICLOS AGRÍCOLAS CONSECUTIVOS APÓS PRÉ-CULTIVO DE ESPÉCIES ADUBOS}

VERDES

Tabela 3. Produtividade de colmos e de açúcar aparente da cana-de-açúcar influenciada pelo cultivo prévio de adubos verdes, média de três cortes e a soma.

\begin{tabular}{|c|c|c|c|c|c|c|c|c|c|c|}
\hline \multirow[t]{3}{*}{ Tratamentos } & \multicolumn{5}{|c|}{ Produtividade de colmos } & \multicolumn{5}{|c|}{ Produtividade de açúcar aparente } \\
\hline & \multirow[b]{2}{*}{$\begin{array}{l}\text { Cana } \\
\text { planta }\end{array}$} & \multicolumn{8}{|c|}{------------------ MG ha'-1--------------------- } & \multirow[b]{2}{*}{ Soma } \\
\hline & & soqueira & soqueira & Média & Soma & Cana planta & soqueira & Soqueira & Média & \\
\hline Mucuna-verde & 129 & 107 & 79 & $105 \mathrm{a}$ & $315 \mathrm{a}$ & 20 & 16 & 11 & $16 \mathrm{a}$ & $47 \mathrm{a}$ \\
\hline Amendoim IAC-Caiapó & 118 & 102 & 91 & $104 \mathrm{a}$ & $311 \mathrm{a}$ & 19 & 15 & 12 & $15 \mathrm{a}$ & $46 \mathrm{a}$ \\
\hline Mucuna-preta & 131 & 99 & 79 & $103 \mathrm{a}$ & $309 \mathrm{a}$ & 21 & 14 & 11 & $15 \mathrm{a}$ & $46 \mathrm{a}$ \\
\hline $\begin{array}{l}\text { Crotalária- júncea IAC- } \\
1\end{array}$ & 133 & 99 & 76 & $103 \mathrm{a}$ & 308 a & 22 & 15 & 11 & $16 \mathrm{a}$ & $48 \mathrm{a}$ \\
\hline Soja IAC-23 & 124 & 104 & 74 & $101 \mathrm{a}$ & $302 \mathrm{a}$ & 20 & 15 & 11 & $15 \mathrm{a}$ & $46 \mathrm{a}$ \\
\hline Girassol IAC-Uruguai & 112 & 104 & 84 & $100 \mathrm{a}$ & $300 \mathrm{a}$ & 18 & 15 & 12 & $15 \mathrm{a}$ & $45 \mathrm{a}$ \\
\hline Feijão-Mungo & 116 & 103 & 77 & $99 \mathrm{a}$ & $296 \mathrm{a}$ & 18 & 15 & 11 & $15 \mathrm{a}$ & $44 \mathrm{a}$ \\
\hline Guandu IAC-fava larga & 121 & 102 & 71 & $98 \mathrm{a}$ & $294 \mathrm{a}$ & 20 & 15 & 10 & $15 \mathrm{a}$ & $45 \mathrm{a}$ \\
\hline Guandu IAC-anão & 119 & 104 & 72 & $98 \mathrm{a}$ & $295 \mathrm{a}$ & 18 & 15 & 10 & $15 \mathrm{a}$ & $43 \mathrm{a}$ \\
\hline Girassol IAC-Iarama & 114 & 101 & 78 & $98 \mathrm{a}$ & 293 a & 18 & 15 & 11 & $15 \mathrm{a}$ & $44 \mathrm{a}$ \\
\hline Amendoim IAC-Tatu & 115 & 99 & 75 & $96 \mathrm{a}$ & 289 a & 19 & 15 & 11 & $15 \mathrm{a}$ & $45 \mathrm{a}$ \\
\hline Mucuna-cinza & 116 & 90 & 68 & $91 \mathrm{~b}$ & $274 \mathrm{~b}$ & 19 & 13 & 10 & $14 \mathrm{~b}$ & $42 \mathrm{a}$ \\
\hline Testemunha campinada & 94 & 79 & 79 & $84 \mathrm{~b}$ & $252 \mathrm{~b}$ & 15 & 12 & 11 & $13 \mathrm{~b}$ & $38 \mathrm{~b}$ \\
\hline Média & $118 \mathrm{~A}$ & $100 \mathrm{~B}$ & $77 \mathrm{C}$ & & & $19 \mathrm{~A}$ & $15 \mathrm{~B}$ & $11 \mathrm{C}$ & & \\
\hline $\mathrm{CV}^{*}(\%)$ & 16,011 & amento & 15,581 & poca & & 16,22 Tra & amento & 16,18 & poca & \\
\hline
\end{tabular}

Médias seguidas de mesma letra pertencem ao mesmo agrupamento pelo teste de Scott-Knott a $5 \%$ de probabilidade. 
Os pesquisadores que trabalham com decomposição da matéria orgânica consideram que se a relação $\mathrm{C} / \mathrm{N}$ se encontra na faixa de 10 a 12:1 ocorre liberação de $\mathrm{N}$ da matéria orgânica do solo. Com relação a resíduos orgânicos, entre 25 e 35:1 ocorre decomposição sem imobilização de $\mathrm{N}$ do solo e acima desses valores ocorre imobilização.

Quando se encontra baixa relação $\mathrm{C} / \mathrm{N}$ observa-se uma rápida decomposição e seus nutrientes ficam liberados rapidamente. Ressalta-se, entretanto, que esses processos ocorrem simultaneamente, podendo ocorrer imobilização e mineralização do mesmo "pool” de N presente no solo.

A rápida decomposição implica na dificuldade de formar palha na superfície devido a rápida degradação do material vegetal, o que não vai ocorrer com os girassóis que apresentaram relação $\mathrm{C}: \mathrm{N}$ acima de 80.

Os baixos valores encontrados de NFBN para a soja, os guandus e o amendoim Tatu (Tabela 6) podem decorrer do fato da amostragem ter sido feita aos 120 dias após semeadura. Nessa fase a planta se encontrava em fase adiantada de maturação das vagens e grande parte do nitrogênio já translocado para os grãos.
Perin et al. (2006) encontraram uma quantidade de nitrogênio vindo da fixação biológica $(\mathrm{FBN})$ presente na parte aérea da crotalária-júncea $(57 \%)$ quando cultivada isoladamente e $61 \%$ quando crescida consorciada com milheto (na proporção de sementes de $50 \%+50 \%$ ). Esses resultados são concordantes com os obtidos neste estudo, em que $C$. juncea fixou em torno de $54 \%$ do total de seu nitrogênio.

De modo geral a soja, o guandu-anão, a mucuna-preta, os amendoins e o girassol IAC-Iarama apresentaram maiores teores em pelo menos um dos macronutrientes na parte aérea em comparação às mucunas verde e cinza, crotalária-júncea, feijão-mungo e girassol IAC-Uruguai (Tabela 4). Entretanto a quantidade aportada ao sistema (conteúdo de nutrientes) foi a menor devido a baixa biomassa seca produzida (Tabela 5). Todavia, a crotalária-júncea produziu grande quantidade de biomassa e forneceu maiores quantidades de nutrientes, principalmente o nitrogênio.

Os maiores conteúdos de nutrientes foram observados em crotalária-júncea e guandu IAC-Fava larga (Tabela 5). Cáceres \& Alcarde, (1995) encontraram acúmulos de 235 e $102 \mathrm{~kg} \mathrm{ha}^{-1}$ de nitrogênio e potássio, respectivamente para Crotalária-júncea. $\mathrm{Na}$ Mucuna-preta foi de 81 e $37 \mathrm{~kg} \mathrm{ha}^{-1}$ de 
nitrogênio e potássio, respectivamente. Esses resultados indicam o grande potencial de incorporação de nitrogênio e reciclagem de potássio por meio da Mucuna-preta e em especial pela crotalária-júncea.

O amendoim IAC-Caiapó, crotaláriajúncea, as mucunas preta, cinza e verde, e o guandu IAC-Fava larga foram as plantas que apresentaram maiores teores de nitrogênio e os girassóis os menores valores, confirmando a elevada fixação biológica de nitrogênio que determina esse resultado (Tabela 5).

Tabela 4. Média dos teores de macro nutrientes contidos nos adubos verdes utilizados em précultivo na cana-de-açúcar, Piracicaba-SP, 2010.

\begin{tabular}{lccccc}
\hline Tratamentos & $\mathrm{N}$ & $\mathrm{P}$ & $\mathrm{K}$ & $\mathrm{Ca}$ & $\mathrm{Mg}$ \\
\hline Soja IAC-23 & $-------------\cdot$ \\
Mucuna-cinza & $31,93 \mathrm{a}$ & $1,61 \mathrm{c}$ & $3,75 \mathrm{~d}$ & $11,90 \mathrm{a}$ & $7,56 \mathrm{~b}$ \\
Guandu IAC-anão & $23,30 \mathrm{~b}$ & $1,99 \mathrm{~b}$ & $12,32 \mathrm{~b}$ & $9,47 \mathrm{~b}$ & $3,51 \mathrm{c}$ \\
Mucuna-preta & $21,19 \mathrm{~b}$ & $2,34 \mathrm{a}$ & $8,18 \mathrm{c}$ & $6,30 \mathrm{c}$ & $2,92 \mathrm{c}$ \\
Crotalária-júncea IAC-1 & $20,97 \mathrm{~b}$ & $1,65 \mathrm{c}$ & $16,33 \mathrm{a}$ & $8,24 \mathrm{c}$ & $3,19 \mathrm{c}$ \\
Mucuna-verde & $20,72 \mathrm{~b}$ & $1,71 \mathrm{c}$ & $10,69 \mathrm{c}$ & $7,61 \mathrm{c}$ & $4,68 \mathrm{c}$ \\
Amendoim IAC-Caiapó & $19,36 \mathrm{~b}$ & $1,51 \mathrm{c}$ & $13,95 \mathrm{~b}$ & $7,96 \mathrm{c}$ & $3,53 \mathrm{c}$ \\
Guandu IAC-fava larga & $17,63 \mathrm{~b}$ & $1,12 \mathrm{~d}$ & $17,54 \mathrm{a}$ & $10,77 \mathrm{~b}$ & $7,53 \mathrm{~b}$ \\
Amendoim IAC-Tatu & $17,50 \mathrm{~b}$ & $1,64 \mathrm{c}$ & $7,77 \mathrm{c}$ & $5,85 \mathrm{c}$ & $2,47 \mathrm{c}$ \\
Feijão-Mungo & $10,88 \mathrm{c}$ & $0,95 \mathrm{~d}$ & $8,15 \mathrm{c}$ & $9,85 \mathrm{~b}$ & $8,49 \mathrm{a}$ \\
Girassol IAC-Iarama & $9,91 \mathrm{c}$ & $1,33 \mathrm{c}$ & $5,30 \mathrm{~d}$ & $6,19 \mathrm{c}$ & $7,51 \mathrm{~b}$ \\
Girassol IAC-Uruguai & $4,69 \mathrm{~d}$ & $0,46 \mathrm{e}$ & $7,47 \mathrm{c}$ & $12,96 \mathrm{a}$ & $9,65 \mathrm{a}$ \\
\hline Média & $3,85 \mathrm{~d}$ & $0,31 \mathrm{e}$ & $10,27 \mathrm{c}$ & $10,24 \mathrm{~b}$ & $7,48 \mathrm{~b}$ \\
\hline CV(\%) & 16,83 & 1,38 & 10,14 & 8,94 & 5,71 \\
\hline
\end{tabular}

* - transformação em raiz quadrada (x). **: média de cinco repetições; Médias seguidas de mesma letra pertencem ao mesmo agrupamento peloteste de Scott-Knott a $5 \%$ de probabilidade. 
Tabela 5. Média dos acúmulos de macro e micronutrientes contidos nos adubos verdes utilizados em pré-cultivo na cana-de-açúcar, Piracicaba-SP, 2010.

\begin{tabular}{|c|c|c|c|c|c|}
\hline Tratamentos & $\mathrm{N}$ & $\mathrm{P}$ & $\mathrm{K}$ & $\mathrm{Ca}$ & $\mathrm{Mg}$ \\
\hline & \multicolumn{5}{|c|}{ 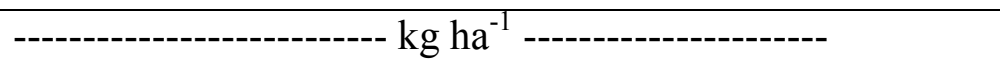 } \\
\hline Crotalária-júncea IAC-1 & $510,47 \mathrm{a}$ & $41,84 \mathrm{a}$ & $257,20 \mathrm{a}$ & $188,03 \mathrm{a}$ & $10,91 \mathrm{c}$ \\
\hline Guandu IAC-fava larga & $403,45 \mathrm{a}$ & $37,76 \mathrm{a}$ & $175,20 \mathrm{~b}$ & $130,52 \mathrm{a}$ & $33,59 \mathrm{c}$ \\
\hline Guandu IAC-anão & $289,49 \mathrm{~b}$ & $32,09 \mathrm{a}$ & $108,98 \mathrm{c}$ & $128,79 \mathrm{a}$ & $55,84 \mathrm{~b}$ \\
\hline Soja IAC-23 & $288,39 \mathrm{~b}$ & $14,47 \mathrm{~b}$ & $33,97 \mathrm{~d}$ & $107,22 \mathrm{a}$ & $33,93 \mathrm{c}$ \\
\hline Mucuna-preta & $214,35 \mathrm{c}$ & $17,43 \mathrm{~b}$ & $168,43 \mathrm{~b}$ & $82,95 \mathrm{~b}$ & $114 \mathrm{a}$ \\
\hline Mucuna-cinza & $158,18 \mathrm{c}$ & $13,93 \mathrm{~b}$ & $83,92 \mathrm{c}$ & $68,25 \mathrm{~b}$ & $19,53 \mathrm{c}$ \\
\hline Mucuna-verde & $180,56 \mathrm{c}$ & $16,01 \mathrm{~b}$ & $127,30 \mathrm{c}$ & $73,57 \mathrm{~b}$ & $26,24 \mathrm{c}$ \\
\hline Amendoim IAC-Tatu & $26,33 \mathrm{~d}$ & $2,38 \mathrm{c}$ & $24,27 \mathrm{~d}$ & $25,89 \mathrm{c}$ & $23,26 \mathrm{c}$ \\
\hline Amendoim IAC-Caiapó & $26,54 \mathrm{~d}$ & $1,65 \mathrm{c}$ & $27,30 \mathrm{~d}$ & $15,89 \mathrm{c}$ & $10,91 \mathrm{c}$ \\
\hline Girassol IAC-Uruguai & $20,37 \mathrm{~d}$ & $1,62 \mathrm{c}$ & $103,08 \mathrm{c}$ & $96,87 \mathrm{~b}$ & $67,96 \mathrm{~b}$ \\
\hline Feijão-Mungo & $27,78 \mathrm{~d}$ & $3,69 \mathrm{c}$ & $15,15 \mathrm{~d}$ & $19,72 \mathrm{c}$ & $43,93 \mathrm{c}$ \\
\hline Girassol IAC-Iarama & $28,17 \mathrm{~d}$ & $3,76 \mathrm{c}$ & $51,86 \mathrm{~d}$ & $68,88 \mathrm{~b}$ & $55,7 \mathrm{~b}$ \\
\hline Média & 181,17 & 15,55 & 98,05 & 83,88 & 42,21 \\
\hline CV $(\%)$ & 54,1 & $36,10 * *$ & $27,66^{*}$ & $16,40 * *$ & 41,70 \\
\hline
\end{tabular}


Tabela 6. Concentração de carbono e nitrogênio, relação C: $\mathrm{N}$ e $\mathrm{N}$ derivado da fixação simbiótica do nitrogênio (FBN) na parte aérea dos adubos verdes utilizados em pré-cultivo na cana-de-açúcar, Piracicaba-SP, 2010.
Culturas utilizadas
$\mathrm{C}$
$\mathrm{N}$
$\mathrm{C}: \mathrm{N}$
N-FBN

em pré-cultivo na cana-de-açúcar

\begin{tabular}{|c|c|c|c|c|}
\hline \multirow[b]{2}{*}{ Amendoim IAC-Caiapó } & \multicolumn{2}{|c|}{------------g kg ${ }^{-1}$--------- } & \multicolumn{2}{|c|}{$\%$} \\
\hline & 424 & 18 & 24 & 68 \\
\hline Crotalária-júncea IAC 1 & 449 & 21 & 21 & 54 \\
\hline Amendoim IAC-Tatu & 430 & 11 & 39 & 35 \\
\hline Mucuna-preta & 446 & 42 & 11 & 76 \\
\hline Guandu IAC-fava larga & 441 & 18 & 25 & 41 \\
\hline Guandu IAC-anão & 446 & 21 & 21 & 30 \\
\hline Soja IAC-23 & 426 & 32 & 13 & 27 \\
\hline Mucuna-cinza & 430 & 23 & 19 & 66 \\
\hline Mucuna-verde & 438 & 19 & 23 & 66 \\
\hline Feijão-Mungo & 426 & 13 & 33 & 98 \\
\hline Girassol IAC-Uruguai & 429 & 4 & 107 & - \\
\hline Girassol IAC-Iarama & 432 & 5 & 86 & - \\
\hline
\end{tabular}

\section{CONCLUSÕES}

A crotalária-júncea, as mucunas (preta, cinza e verde) e os guandus (IACanão e IAC-fava larga) apresentam maior produção de material vegetal fresco e a crotalária-júncea e os guandus (IAC-anão e IAC-fava larga) o maior valor para material vegetal seco.
Os adubos verdes apresentam maior controle efetivo do mato que as plantas alimentícias, sendo que as mucunas, verde e cinza, foram mais eficientes no controle das plantas daninhas que o controle manual capinado.

A crotalária-júncea IAC-1 e a mucuna-preta proporcionaram maior produtividade física de colmos e de açúcar. 
Os adubos verdes não interferem na infestação natural da broca da cana-deaçúcar (Diatraea saccharalis) e melhoram o perfilhamento da cana-planta.

\section{AGRADECIMENTOS}

Ao $\mathrm{CNPq}$ pelo apoio (bolsa de produtividade em pesquisa do primeiro autor).

\section{REFERÊNCIAS BIBLIOGRÁFICAS}

AKAIKE, H. 1974. A new look at the statistical model identification. IEEE Transaction on Automatic Control, New York, AC-19, p.716-723.

AMBROSANO, E.J.; WUTKE, E.B.; BRAGA, N.R.; MIRANDA, M.A.C. 1999. Leguminosas: alternativas para produção ecológica de grãos em diferentes regiões agroecológicas do Estado de São Paulo. In: AMBROSANO, E.J. coord. Agricultura Ecológica. 1ed. Guaíba: Agropecuária, p.161-178.

AMBROSANO, E.J.; AMBROSANO, R.B.; WUTKE, E.B.; BULISANI, E.A.; ROSSI, F.; GUIRADO, N.; ROS, F.B.; MENDES, P.C.D.; BATELOCHI, L.R. 2003. Produção de brotos comestíveis: Feijão-mungo (Vigna radiata) In: Anais da III Feira da Pequena Agroindustria. CATI, Campinas, 143p.

AMBROSANO, E.J.; TRIVELIN, P.C.O.; CANTARELLA, H.; AMBROSANO, G.M.B.; SCHAMMAS, E.A.; GUIRADO, N.; ROSSI, F.; MENDES, P.C.D.; MURAOKA, T. 2005. Utilization of nitrogen from green manure and mineral fertilizer by sugarcane. Scientia Agricola, Piracicaba, v.62, n.3, p. 534-542.
AMBROSANO, E.J.; AZCÓN R.; CANTARELLA, H.; AMBROSANO, G.M.B.; SCHAMMASS, E.A.; TRIVELIN, P.C.O.; MURAOKA, T; ROSSI, F.; GUIRADO, N.; UNGARO, M.R.G.; TERAMOTO J.R.S. 2010. Crop rotation biomass and arbuscular mycorrhizal fungi effects on sugarcane yield. Scientia Agricola, Piracicaba, v.67, n. 3. p. 692-701.

AMBROSANO, E.J.; AMBROSANO, G. M. B.; AZCÓN, R.; CANTARELLA, H.; DIAS F.L.F.; MURAOKA, T.; TRIVELIN, P.C.O.; ROSSI, F.; SCHAMMASS, E.A.; SACHS R.C.C. 2011. Produtividade da cana-de-açúcar após o cultivo de leguminosas. Bragantia, Campinas, v. 70, n. 4, p. 19.

AMBROSANO, E. J; TRIVELIN, P. C. O.; CANTARELLA, H.; AMBROSANO, G. M. B.; SCHAMMASS, E. A.; MURAOKA, T.; ROSSI, F. $2011 \mathrm{a} .{ }^{15} \mathrm{~N}-$ Labeled Nitrogen from Green Manure and Ammonium Sulfate Utilization by the Sugarcane Ratoon. Scientia Agricola, Piracicaba, v.68, n.6, p.361368.

ARÉVALO, R.A.; GUIRADO, N.; PRATES, H.S. 2004. Manejo sustentável de plantas daninhas (matoespecies) da agricultura orgânica. In: AMBROSANO et al. (Coord.). Curso de Capacitação em Agricultura Orgânica. Campinas. CATI, 231p.

AZCÓN, R. 1999. Importancia de los Microrganismos rizosféricos en el crecimiento, nutrición vegetal $\mathrm{y}$ sostenibilidad agrícola. In: AMBROSANO, E. J. Agricultura Ecológica. $1^{a}$ ed. Guaíba, RS: Livraria e Editora Agropecuária LTDA, v. 1. 398 $\mathrm{p}$.

AZCÓN, R.; RUBRO, R.; BAREA, J.M. 1991. Selective interactions between different species of mycorrhizal fungi and Rhizobium meliloti strains and 
theirs effects on growth, N2 fixation $(15 \mathrm{~N})$ and nutrition of Medicago sativa L. New Phytologist, Cambridge, v.117, n. 3, p. 399-404.

BATAGLIA, O.C.; FURLANI, A.M.C.; TEIXEIRA; J.P.F.; FURLANI, P.R.; GALLO, J.R. 1983. Métodos de análises químicas de plantas. Campinas: Instituto Agronômico, 48p. (Boletim Técnico, 78).

CÁCERES, N.T.; ALCARDE, J.C. 1995. Adubação verde com leguminosas em rotação com cana-de-açucar. Revista STAB, Piracicaba, v.13 n.1, p.16-20.

CHAPMAN, L.S.; HOGARTH, D.M.; LEVERINGTON, K.C. 1983. Does nitrogen fertilizer carry over to succeeding crops. In: AUSTRALIAN SOCIETY OF SUGAR CANE TECHNOLOGISTS CONGRESS, 22, Brisbane, $1983 . \quad$ Proceedings. Brisbane: Watson Fergunson, p. 109114.

ERASMO, E.A.L., AZEVEDO, W.R., SARMENTO, R.A. 2004. Potencial de espécies utilizadas como adubo verde no manejo integrado de plantas daninhas. Planta daninha, Viçosa, v.22, n. 4, p. 337-342.

ESPÍNDOLA, J.A.A.; ALMEIDA, D.L.; GUERRA, J.G.M.; SILVA, E.M.R.; SOUZA, F.A. 1998. Influência da adubação verde na colonização micorrízica e na produção da batatadoce. Pesquisa Agropecuária Brasileira, Brasília, v.33, n.3, p.339347.

ESPÍNDOLA, J.A.A.; GUERRA, J.G.M.; ALMEIDA, D.L. 2004. Estratégias para utilização de leguminosas para adubação verde em unidades de produção agroecológica. Seropédica: EmbrapaAgrobiologia, 24p. (Embrapa-CNPAB. Documentos, 174).

FERREIRA, D.F. 2008. SISVAR: Um programa para análises e ensino de estatística. Revista Symposium, Lavras, v. 6, n.2, p. 36-41,

GALLO, D.; NAKANO, O. SILVEIRA NETO, S.; CARVALHO, R.P.L.; BAPTISTA, G.C.; BERTI FILHO, E.; PARRA, J.R.P..; ZUCCHI, R.A.; ALVES, S.B.; VENDRAMIM, J.D.; MARCHINI, L.C.; LOPES, J.R.S.; OMOTO, C., 2002. Entomologia Agrícola, Piracicaba, FEALQ, 920p.

GIOVANETTI, M.; MOSSE, B. 1980. An evaluction of techniques for measuring vesicular arbuscular mycorrhizal spores. New Phytologist, Oxford, v.84, n.3, p.489-500.

IBGE. 2010. Systematic Survey of Agricultural Production. Disponível em: http://www.sidra.ibge.gov.br/bda/default .asp? $\mathrm{t}=5 \& \mathrm{z}=\mathrm{t} \& \mathrm{o}=1 \& \mathrm{u} 1=1 \& \mathrm{u} 2=1 \& \mathrm{u} 3=1$ $\& u 4=1 \& u 5=1 \& u 6=1 \& u 7=1 \& u 8=1 \& u 9$ $=3 \& u 10=1 \& u 11=26674 \& u 12=1 \& u 13=$ 1\&u14=1. Acesso: Setembro de 2014.

LITTEL, R.C.; MILLIKEN, G.A.; STROUP, W.W.; WOLFINGER, R.D. 1996. SAS System for mixed models. Cary: N.C.SAS Institute Inc., 633p.

MASCARENHAS, H.A.A; TANAKA,R.T.; COSTA, A.A.; ROSA, F.V.; COSTA, F.V. 1994. Efeito residual das leguminosas sobre o rendimento físico e econômico da cana-planta. Campinas: Instituto Agronômico, 15 p. (Boletim Científico, 32).

ORLANDO FILHO, J.; RODELLA, A.A.; BELTRAME, J.A.; LAVORENTI, N.A. 1999. Doses, fontes e formas de aplicação de nitrogênio em cana-deaçúcar. Revista STAB, Piracicaba, v.17, n.4, p.39-41,

PANJA, B.N.; CHAUDHURI S. 2004. Exploitation of soil arbuscular mycorrhizal potential for AM-dependent mandarin orange plants by pre-cropping with mycotrophic crops. Applied Soil Ecology, Oxford, v. 26, n.2, p.249-255.

PHILIPS, J.M.; HAYMAN, D.S. 1970. Improved procedures for cleaning roots 
and staining parasitic and vesicular arbuscular mycorrhizal fungi for rapid assessment of infection. Transactions of the British Mycological Society, London, v.55, n. 1, p.158-162,

SAS Institute. 2004. SAS/STAT Software: changes and enhancements through release 8.2. Cary: Statistical System Institute, $1028 \mathrm{p}$.

TANIMOTO, T. 1964. The press method of cane analysis. Hawaiian Planter's Record, Hawaii, v.57, n.2, p.133-150.

Recebido em: 22/2/2013 Aceito para publicação em: 24/112014 